\title{
Quantitative Determination of Lattice Fluoride Effects on the Solubility and Crystallinity of Carbonated Apatites with Incorporated Fluoride
}

\author{
G. Yan ${ }^{\text {a }}$ K. Moribe ${ }^{c}$ M. Otsuka ${ }^{\text {d }}$ K. Papangkorn ${ }^{\text {b }}$ W.I. Higuchi ${ }^{\text {b }}$ \\ a Department of Biomedical and Pharmaceutical Sciences, Idaho State University, Pocatello, Idaho, and \\ ${ }^{b}$ Department of Pharmaceutics and Pharmaceutical Chemistry, University of Utah, Salt Lake City, Utah, USA; \\ 'Graduate School of Pharmaceutical Sciences, Chiba University, Chiba, and ${ }^{\mathrm{d}}$ Research Institute of Pharmaceutical \\ Sciences, Faculty of Pharmacy, Musashino University, Musashino, Japan
}

\section{Key Words}

Caries $\cdot$ Crystallinity $\cdot$ Dental mineral $\cdot$ Fluoride $\cdot$ Lattice $\cdot$ Solubility

\begin{abstract}
The purpose of this study was to evaluate quantitatively the effects of fluoride on the solubility and crystallinity of carbonated apatites (CAPs) after its incorporation into the crystal lattice using the metastable equilibrium solubility (MES) distribution method. Fluoride-incorporated CAPs (F-CAPs) of two different carbonate levels ( 3 and 5\%) and fluoride contents from 0 to $20,000 \mu \mathrm{g} / \mathrm{g}$ were synthesized. X-ray diffraction experiments and Rietveld analysis were conducted to obtain crystallite microstrain and unit cell parameters. Acetate buffer MES solution media were prepared at two solution fluoride concentrations ( 0.2 and $2.0 \mathrm{mg} / \mathrm{l})$ and at two $\mathrm{pHs}$ (5.0 and 5.7). The unit cell a-axis values of the F-CAPs were found to decrease as the fluoride content increased, consistent with the fluoride being incorporated into the crystal lattice. The fluoride concentrations in the MES solution media were high enough to provide a 'swamping' effect such that the fluoride released from the F-CAPs during dissolution was minimal in changing the solution fluoride concentration. Employing the MES distribution superposition
\end{abstract}

method, it was shown that the surface complex possessing the fluorapatite (FAP) stoichiometry $\left[\mathrm{Ca}_{10}\left(\mathrm{PO}_{4}\right)_{6} \mathrm{~F}_{2}\right]$ accounted for the MES distribution behavior of all experiments. In addition, the mean $\mathrm{pl}_{\mathrm{FAP}}$ [the value of $-\log \left(\mathrm{a}_{\mathrm{Ca}}{ }^{10} \mathrm{apO}_{4}{ }^{6} \mathrm{a}_{\mathrm{F}}{ }^{2}\right) \mathrm{cal}-$ culated from the ionic activity product based on FAP stoichiometry of the MES dissolution media in which $50 \%$ of the F-CAPs had dissolved] correlated well with the crystallite microstrain parameters of the F-CAPs. The incorporated fluoride in the F-CAPs showed only modest effects on F-CAP crystallinity and solubility.

Copyright $\odot 2012$ S. Karger AG, Basel

In 1942, Dean et al. demonstrated that there was an inverse relationship between the fluoride level in drinking water and the incidence of dental caries. Since then, the fluoride effect in the prevention of dental caries has been intensively investigated and two mechanisms for the fluoride cariostatic effect have been proposed: a lattice fluoride effect and a solution fluoride effect. In the case of the lattice fluoride effect, fluoride incorporated into tooth mineral crystals during tooth development is believed to form tooth mineral with higher crystallinity and lower solubility, such as fluorapatite (FAP) [McKay, 1952; Glenn et al., 1982; LeGeros et al., 1985]. In the case of the

\section{KARGER}

Fax +4161306 1234 E-Mail karger@karger.ch www.karger.com

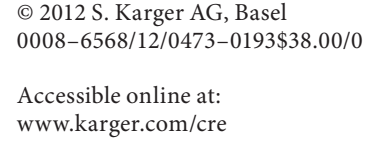

Guang Yan

Department of Biomedical and Pharmaceutical Sciences, Idaho State University 970 S 5 th Ave

Pocatello, ID 83209 (USA)

E-Mail guang.yan@pharmacy.isu.edu 
solution fluoride effect, fluoride in the solution environment, such as saliva, would inhibit the dissolution of tooth mineral [Wong et al., 1987]. Studies have shown that dental mineral dissolution rates are significantly reduced in acidic solutions with low levels of fluoride present [Margolis et al., 1986; Takagi et al., 2000] and solution fluoride of $0.1-2 \mathrm{mg} / \mathrm{l}$ may accelerate the seeded crystal growth of fluoridated hydroxyapatite (HAP) [Varughese and Moreno, 1981]. Although there is controversy with regard to which effect is more important in the prevention of dental caries [Widenheim et al., 1986; DePaola, 1991; Glenn, 2000], more researchers tend to believe that the solution fluoride effect is the more important effect [Thylstrup, 1990; Featherstone, 2000; Rosin-Grget and Lincir, 2001]. This could be due to multiple studies of the lattice fluoride effect on the crystallinity and the solubility of fluoride-incorporated apatites, showing that there was no clear correlation between fluoride substitution level and apatite crystallinity and also no correlation between crystallinity and the dissolution tendency of those apatites [Driessens, 1973; Moreno et al., 1974, 1977; Okazaki et al., 1981, 1982]. However, there is a lack of research that provides a direct comparison between the lattice fluoride effect and the solution fluoride effect.

There are significant variations in the dental enamel solubility product (Ksp) determined in previous studies [Patel and Brown, 1975; Larsen and Jensen, 1989], possibly due to the impurities and defects present in enamel crystals. However, several studies [LaMer, 1962; Rootare and Deitz, 1962] have also shown that the Ksp of HAP preparations varies with initial solution composition and slurry density (solid-to-solution ratio), contrary to the thermodynamic principle. Carbonated apatite (CAP), a type of apatite with carbonate incorporated into the HAP crystals that therefore may mimic the composition of dental enamel, also shows a similar behavior of solubility dependence on slurry density [Hsu, 1993]. It is clear that the solubility behavior of dental enamel, HAP, or CAP cannot be explained by conventional thermodynamic approaches. Researchers have proposed a precipitated phase or surface complex of calcium phosphate, such as $\mathrm{CaHPO}_{4} \cdot 2 \mathrm{H}_{2} \mathrm{O}$ [Levinskas and Neuman, 1955], $\mathrm{Ca}_{2}\left(\mathrm{HPO}_{4}\right)(\mathrm{OH})_{2}$ [LaMer, 1962] or $\mathrm{Ca}_{3}\left(\mathrm{PO}_{4}\right)_{2}$ [MacGregor and Nordin, 1960], other than the dental mineral or apatites, to explain their solubility behavior. Mir et al. [1969] first proposed a surface complex with FAP stoichiometry controlling the dissolution of powdered enamel in the presence of low concentrations of fluoride in solution. In addition, Moreno et al. [1977], Brown et al. [1977], and Driessens [1979] also postulated the existence of a precipitation phase or surface complex of FAP controlling the solubility of the fluoride-substituted apatites.

More recently, Higuchi's research group observed that the solubility behavior of CAPs in weak acid buffers demonstrates a metastable equilibrium solubility (MES) distribution phenomenon [Hsu et al., 1994; Baig et al., 1996, 1999a; Chhettry et al., 1999]. The concept of an MES distribution is: a CAP sample is a heterogeneous mixture of crystal domains with different solubilities; in a series of weak acid buffer solutions with different ionic activity product (IAP) values, which correspond to different solution saturation levels, only the CAP domains with solubility larger than the solution IAP value will dissolve in the solution rapidly (within hours or days); crystallization processes in the dissolution media are extremely slow, thus the undissolved CAP crystals maintain a metastable equilibrium with the solution; the solubility of the CAP sample in the particular solution is the MES, and the CAP shows an MES distribution in the series of partially saturated solutions with different IAP values. The investigators observed that the dissolution behavior of CAP in weak acid buffer solutions without fluoride present can be described by a MES distribution governed by a surface complex with a stoichiometry of HAP [Hsu et al., 1994; Chhettry et al., 1999], and the dissolution behavior of CAP in weak acid buffer with fluoride present can be described by a MES distribution governed by a surface complex with a stoichiometry of FAP [Zhuang et al., 2000]. Powdered human dental enamel has also been shown to exhibit MES distribution behavior [Hsu et al., 1994].

In the present study, we synthesized a series of fluoride-incorporated CAPs (F-CAPs) with a range of fluoride substitution levels corresponding to replacing up to $50 \%$ of the hydroxyl ion in the apatite. One of the purposes of this study was to test whether such F-CAPs would exhibit the MES distribution phenomenon in weak acid buffers with the fluoride present. Since the fluoride content of the dissolution media was much higher than the fluoride released to the media from the mineral after dissolution, this method was expected to provide an opportunity to observe the true solubility of such lattice F-CAPs and provide a quantitative evaluation of the lattice fluoride effect on the solubility of F-CAPs.

In addition, it has previously been demonstrated that the microstrain parameter is a better parameter to describe CAP crystallinity, and a good correlation between the microstrain parameter and the CAP MES in weak acid buffers with or without fluoride present has been observed [Baig et al., 1999b; Zhuang et al., 2001]. Accord- 
ingly, another purpose of this paper was to determine how the incorporated fluoride level could affect the mineral crystallinity by means of the microstrain parameter and whether there is a correlation between the MES and the microstrain parameters for the F-CAPs. Through this study we expected to have more quantitative understanding of the lattice fluoride effect on dental mineral crystallinity and solubility.

\section{Materials and Methods}

\section{Preparation of F-CAPs}

Two series of F-CAPs with varying fluoride contents at two carbonate levels ( 3 and $5 \%$ ) were prepared by a precipitation method [Papangkorn et al., 2008] at $85 \pm 0.5^{\circ} \mathrm{C}$ (termed $3 \%$ series and $5 \%$ series for the 3 and $5 \%$ carbonate content, respectively). Seven samples in each series were synthesized by feeding $200 \mathrm{ml}$ of $0.6 \mathrm{M} \mathrm{Ca}\left(\mathrm{NO}_{3}\right)_{2}$ solution and $200 \mathrm{ml}$ of $0.36 \mathrm{M} \mathrm{Na}_{2} \mathrm{HPO}_{4}$ solution containing $0-33.7 \mathrm{~mm} \mathrm{NaF}$ and 31.5 or $69.0 \mathrm{~mm} \mathrm{NaHCO}$ at $1.4 \mathrm{ml} / \mathrm{min}$ by two peristaltic pumps (P-1, Pharmacia Biotech) into a 5 -liter flask under stirred conditions. The two solutions were fed into the 5-liter flask containing 4 liters of doubly deionized water pre-equilibrated to $85^{\circ} \mathrm{C}$. The stirring speed was controlled at $200 \mathrm{rpm}$ by a Stirrer BDC2002 (Caframo) and the $\mathrm{pH}$ was maintained at 9.0 by titration with $1 \mathrm{M} \mathrm{NaOH}$ solution using a PHM 290 pH-STAT controller (Radiometer) and an ABU 901 AUTO burette (Radiometer). After the feeding of the calcium and the phosphate/carbonate/fluoride solutions was completed, the mixture was digested for $1 \mathrm{~h}$ under the same conditions. The residue was obtained by filtering the mixture and washed 3 times with doubly deionized water. The final residue was then oven dried at $60^{\circ} \mathrm{C}$ for $48 \mathrm{~h}$. Then the solid was ground into fine powder and stored for later use.

\section{Characterization}

The F-CAPs were analyzed for calcium, phosphate, carbonate, and fluoride content and their specific surface areas were determined. Calcium content was analyzed by the method of Sarkar and Chauhan [1967], phosphate by the method of Gee et al. [1954], and carbonate by the micro diffusion method of Conway [1962]. Fluoride content was determined by dissolving a small amount of the F-CAPs with $1 \mathrm{ml}$ of $1 \mathrm{M} \mathrm{HClO}_{4}$ solution, and then adjusting to $\mathrm{pH} 5.0$ with $\mathrm{NaOH}$; the final solution was measured with a fluoride ion selective electrode (Radiometer) [Barry et al., 2003]. The specific surface area of each F-CAP sample was determined by the BET method with nitrogen as the adsorbate (Monosorb; Quantachrome, New York, N.Y., USA). It was assumed that the F-CAPs were B-type CAPs with a stoichiometry of $\mathrm{Ca}_{10}\left(\mathrm{PO}_{4}\right)_{6-0.67 \mathrm{y}}\left(\mathrm{CO}_{3}\right)_{\mathrm{y}}(\mathrm{OH})_{2-2 \mathrm{x}}(\mathrm{F})_{2 \mathrm{x}}$, where $\mathrm{x}$ and $\mathrm{y}$ were calculated based on the amounts of fluoride and carbonate in the F-CAPs, respectively. The fluoride substitution level, defined as the fraction of hydroxide ions being substituted by the fluoride ions, is the $\mathrm{x}$ value.

X-ray diffraction data were collected with a Siemens D5000 high-resolution powder diffractometer with a curved graphite crystal monochromator in the diffracted beam. $\mathrm{Cu} \mathrm{K} \alpha$ rays were produced at $40 \mathrm{kV}$ and $40 \mathrm{~mA}$ and a step size of $0.02^{\circ}$ was used at
$10 \mathrm{~s} / \mathrm{step}$ in the range of $20-90^{\circ} 2 \theta$ for all F-CAP samples. The microstrain parameter, the crystal size parameter, and the unit cell parameters a and $\mathrm{c}$ were determined through analysis of the X-ray data using the Rietveld refinement method (DBWS 9411 program) [Young et al., 1995; Baig et al., 1999b]. A higher microstrain parameter indicates a lower crystallinity. The larger the crystallite size parameter, the smaller the size of the mineral crystal and therefore the larger the sample specific surface area.

\section{Preparation of the MES Solution}

$\mathrm{NaCl}(4 \mathrm{M})$, sodium acetate $(2 \mathrm{M})$, acetic acid $(2 \mathrm{M}), \mathrm{CaCl}_{2}$ $(1 \mathrm{M})$, and $\mathrm{Na}_{2} \mathrm{HPO}_{4}(1 \mathrm{M})$ stock solutions were prepared. The stock solutions (except acetic acid) were de-fluoridated twice using HAP powder (Bio-Rad) (1 g of HAP per liter of solution stirred for $24 \mathrm{~h}$ each time, and then filtering out the HAP powder), which gave fluoride concentrations of less than $0.1 \mathrm{mg} / \mathrm{l}$. Then a series of $0.1 \mathrm{M}$ acetate buffer solutions were prepared at two fluoride concentrations $(0.2$ and $2 \mathrm{mg} / \mathrm{l})$ to which calculated amounts of $\mathrm{CaCl}_{2}, \mathrm{Na}_{2} \mathrm{HPO}_{4}(\mathrm{Ca} / \mathrm{P}=1.67)$, and standard fluoride solution $(1,000 \mathrm{mg} / \mathrm{l})$ were added in order to attain a predetermined IAP based on the stoichiometry of FAP $\left[\mathrm{Ca}_{10}\left(\mathrm{PO}_{4}\right)_{6} \mathrm{~F}_{2}\right]$. The ionic strength of each of these solutions was adjusted to $0.5 \mathrm{M}$ using $\mathrm{NaCl}$. Then the $\mathrm{pH}$ was adjusted using $1 \mathrm{M} \mathrm{NaOH}$ or $1 \mathrm{M} \mathrm{HCl}$. For most experiments, CHEMIST ${ }^{\mathrm{TM}}$ software (MicroMath, Salt Lake City, Utah, USA) was used in the calculation of the IAP of the MES solutions.

\section{Determination of MES Distribution}

The method used for the determination of the MES of apatites has been previously described [Chhettry et al., 1999; Papangkorn et al., 2008]. Briefly, $10 \mathrm{mg}$ of the F-CAPs were allowed to equilibrate with a series of partially saturated MES solutions for 2 days under stirring at $300 \mathrm{rpm}$ with a stir bar, with the temperature being maintained at $30^{\circ} \mathrm{C}$. In order to prevent significant changes in the IAP of the MES solutions due to dissolution of CAPs in the media, a high solution-to-solid ratio was maintained; typically a 2-liter MES solution volume was used for each $10 \mathrm{mg}$ F-CAP. In most of the experiments, the MES distributions of F-CAPs were determined at $\mathrm{pH}$ 5.7, and in some cases the MES distributions were also determined at $\mathrm{pH}$ 5.0. At the end of the stipulated equilibration time, the undissolved F-CAPs were recovered by filtration through $0.22-\mu \mathrm{m}$ membrane filters. The solid residue was dissolved by $0.1 \mathrm{M} \mathrm{HClO}_{4}$ and analyzed for calcium and phosphate, and the results were then used to calculate the fractions of F-CAPs dissolved in the corresponding MES dissolution media. The $\mathrm{pH}$ of the MES solution postequilibrium was measured and the fluoride concentration of the solution after filtering was determined by a fluoride ion selective electrode. The calcium and phosphate concentrations of the postequilibrium solutions were also measured. Then the IAP based upon the FAP stoichiometry, $\mathrm{pI}_{\mathrm{FAP}}=\left[-\log \left(\mathrm{a}_{\mathrm{Ca}}{ }^{10} \mathrm{a}_{\mathrm{PO}_{4}}{ }^{6} \mathrm{a}_{\mathrm{F}}{ }^{2}\right)\right]$, of the MES solutions after equilibration with the F-CAP solid was calculated from the experimental data. Plots were then made of the fraction of F-CAP dissolved versus the corresponding $\mathrm{pI}_{\mathrm{FAP}}$ of the MES solution after MES equilibrium. The mean $\mathrm{pI}_{\mathrm{FAP}}$ values (the $\mathrm{pI}_{\mathrm{FAP}}$ value at which $50 \%$ of the F-CAP was dissolved) of F-CAPs were determined by fitting the MES distribution data with the error function model using Scientist (MicroMath). 

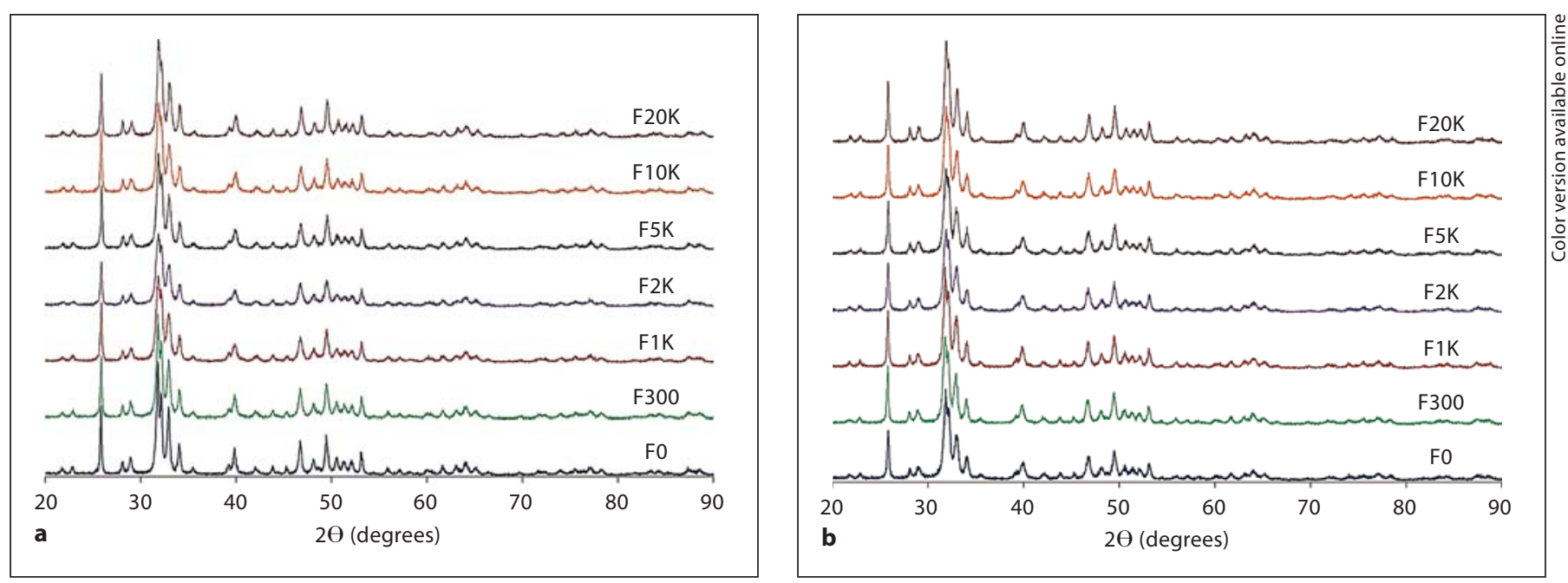

Fig. 1. X-ray diffraction patterns of the F-CAP samples. a 3\% carbonate. b 5\% carbonate.

\section{Results}

\section{Characterization of the F-CAPs}

The chemical compositions of the two series of F-CAPs are listed in table 1, together with the fluoride substitution extent in each F-CAP. There was a linear relationship between the fluoride contents in the F-CAPs and the amounts of $\mathrm{NaF}$ added during synthesis. In addition, the calcium, phosphate and carbonate contents were relatively constant for each series of F-CAPs.

The X-ray powder diffraction patterns for all of the F-CAPs are shown in figure 1 . The microstrain parameters, crystallite size parameters, unit cell a-axis values, unit cell c-axis values, and weighted profile factor $(\mathrm{R}-\mathrm{Wp})$ of the fitting obtained from the Rietveld refinement method are reported in table 2 . Based on the $\mathrm{R}-\mathrm{Wp}$ values, the Rietveld refinement fittings of the X-ray data were good for all of the samples.

The relationships between the unit cell a-axis value and the fluoride substitution extent for both the $3 \%$ and the $5 \%$ series of the F-CAPs are shown in figure $2 \mathrm{a}$. The a-axis value decreases as the fluoride substitution extent increases for both series of F-CAPs. Figure $2 b$ shows the relationship between the microstrain parameter and fluoride content for both the $3 \%$ and the $5 \%$ series of the F-CAPs. The microstrain parameters were smaller in F-CAPs with a high fluoride content, which indicates that such F-CAPs exhibit higher crystallinity. In table 2, we report the specific surface area of each sample determined from the BET experiments. Figure 3 shows the re-
Table 1. Chemical compositions of the two series (3 and 5\% carbonate) of F-CAPs

\begin{tabular}{|c|c|c|c|c|c|}
\hline F-CAPs & $\begin{array}{l}\mathrm{Ca}, \\
\text { wt } \%\end{array}$ & $\begin{array}{l}\mathrm{PO}_{4} \text {, } \\
\text { wt \% }\end{array}$ & $\begin{array}{l}\mathrm{CO}_{3} \\
\text { wt } \%\end{array}$ & $\begin{array}{l}\text { F, } \\
\text { wt } \mu g / g\end{array}$ & $\begin{array}{l}\text { F substi- } \\
\text { tution }^{a}\end{array}$ \\
\hline \multicolumn{6}{|l|}{$3 \%$} \\
\hline F0 & 37.2 & 49.3 & 2.8 & 0 & 0 \\
\hline F300 & 37.0 & 51.5 & 2.7 & 322 & 0.0085 \\
\hline F1K & 36.9 & 51.1 & 3.0 & 959 & 0.0252 \\
\hline $\mathrm{F} 2 \mathrm{~K}$ & 36.9 & 51.5 & 3.0 & 1,993 & 0.0524 \\
\hline F5K & 37.0 & 51.9 & 2.9 & 4,805 & 0.1264 \\
\hline $\mathrm{F} 10 \mathrm{~K}$ & 36.7 & 52.5 & 2.9 & 9,941 & 0.2616 \\
\hline F20K & 36.7 & 50.0 & 2.8 & 18,021 & 0.4742 \\
\hline \multicolumn{6}{|l|}{$5 \%$} \\
\hline F0 & 35.8 & 48.7 & 4.7 & 0 & 0 \\
\hline F300 & 37.1 & 51.1 & 4.2 & 338 & 0.0089 \\
\hline F1K & 36.9 & 49.6 & 4.5 & 932 & 0.0245 \\
\hline $\mathrm{F} 2 \mathrm{~K}$ & 36.5 & 49.0 & 4.6 & 1,937 & 0.0600 \\
\hline F5K & 36.5 & 50.0 & 4.5 & 4,794 & 0.1262 \\
\hline $\mathrm{F} 10 \mathrm{~K}$ & 36.9 & 49.2 & 4.3 & 10,136 & 0.2667 \\
\hline F20K & 37.3 & 48.9 & 4.2 & 19,344 & 0.5090 \\
\hline
\end{tabular}

The number after the F letter in the sample name denotes its approximate fluoride content in $\mu \mathrm{g} / \mathrm{g}$.

${ }^{\text {a }}$ Fraction of $\mathrm{OH}^{-}$replaced by $\mathrm{F}^{-}$.

lationship between the crystallite size parameter and the specific surface areas for both the 3\% and the 5\% series of the F-CAPs. A nonlinear relationship between the crystallite size parameter and the specific surface area is apparent. 

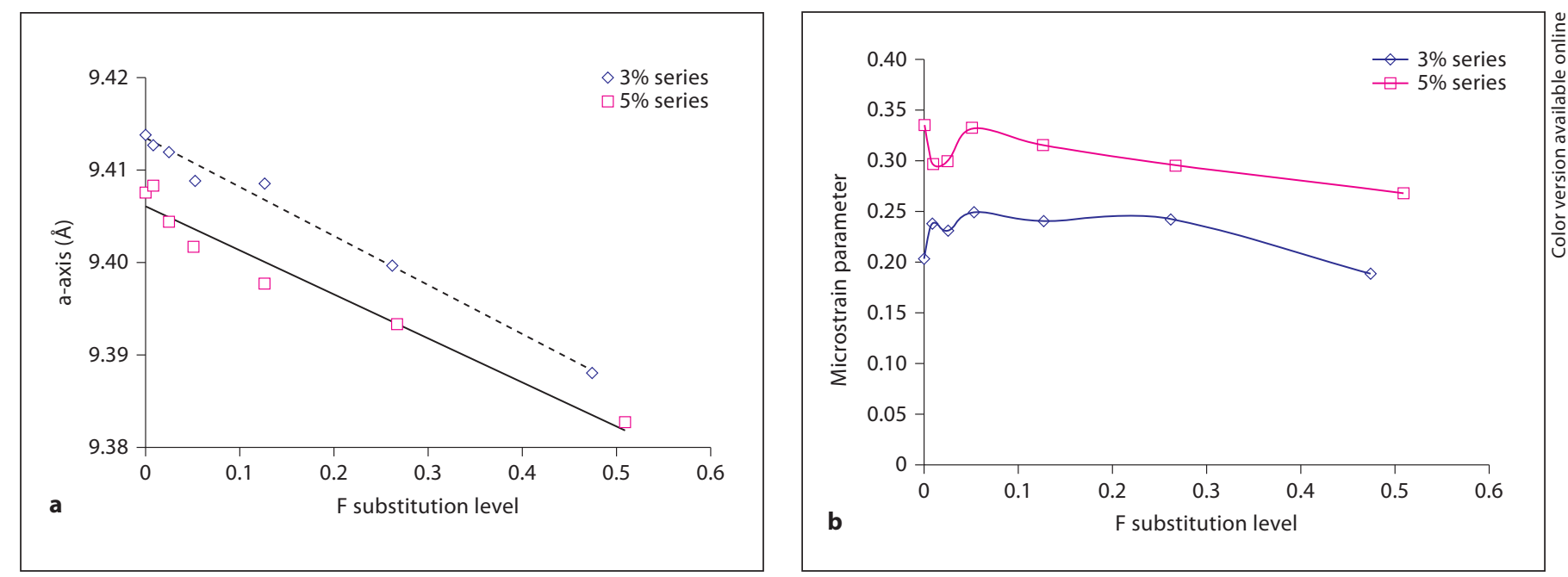

Fig. 2. a Relationship between the fluoride substitution level and the length of the crystallite unit cell a-axis of the F-CAPs (for the $3 \%$ samples, the linear regression equation is $y=-0.0527 x+9.4143, R^{2}=0.9867$; for the $5 \%$ samples, the linear regression equation is $\left.\mathrm{y}=-0.0474 \mathrm{x}+9.4061, \mathrm{R}^{2}=0.9588\right)$. $\mathbf{b}$ Relationship between the fluoride substitution level and the crystallinity (microstrain parameter) of the F-CAPs.

Table 2. Summary of the Rietveld refinement results, mean $\mathrm{pI}_{\mathrm{FAP}}$ values, and surface area of the two series (3 and $5 \%$ carbonate) of F-CAPs

\begin{tabular}{|c|c|c|c|c|c|c|c|}
\hline F-CAPs & $\begin{array}{l}\text { Unit cell } \\
\text { a-axis, } \AA\end{array}$ & $\begin{array}{l}\text { Unit cell } \\
\text { c-axis, } \AA\end{array}$ & $\begin{array}{l}\text { Microstrain } \\
\text { parameters }^{\mathrm{a}}\end{array}$ & $\begin{array}{l}\text { Crystallite size } \\
\text { parameter }^{\mathrm{a}}\end{array}$ & $\begin{array}{l}\mathrm{R}-\mathrm{Wp} \\
\%\end{array}$ & $\begin{array}{l}\text { Mean } \\
\text { pI }_{\text {FAP }}\end{array}$ & $\begin{array}{l}\text { Surface area, } \\
\mathrm{m}^{2} / \mathrm{g}\end{array}$ \\
\hline \multicolumn{8}{|l|}{$3 \%$} \\
\hline F0 & 9.4139 & 6.8888 & $0.2037(187)$ & $0.1882(88)$ & 14.28 & 116.74 & 28.227 \\
\hline F300 & 9.4127 & 6.8882 & $0.2383(197)$ & $0.2203(94)$ & 14.50 & 116.31 & 31.354 \\
\hline $\mathrm{F} 1 \mathrm{~K}$ & 9.4120 & 6.8885 & $0.2314(209)$ & $0.2693(97)$ & 14.42 & 115.64 & 42.265 \\
\hline $\mathrm{F} 2 \mathrm{~K}$ & 9.4089 & 6.8897 & $0.2495(229)$ & $0.2928(109)$ & 15.28 & 115.49 & 48.012 \\
\hline F5K & 9.4086 & 6.8883 & $0.2405(200)$ & $0.2536(95)$ & 14.27 & 115.73 & 41.038 \\
\hline F10K & 9.3997 & 6.8894 & $0.2427(208)$ & $0.2510(98)$ & 14.65 & 116.14 & 38.957 \\
\hline F20K & 9.3881 & 6.8895 & $0.1887(200)$ & $0.2444(95)$ & 14.86 & 116.57 & 31.874 \\
\hline \multicolumn{8}{|l|}{$5 \%$} \\
\hline F0 & 9.4076 & 6.8946 & $0.3353(229)$ & $0.2370(105)$ & 14.28 & 113.68 & 45.284 \\
\hline F300 & 9.4084 & 6.8927 & $0.2967(215)$ & $0.2134(102)$ & 15.07 & 114.42 & 30.450 \\
\hline $\mathrm{F} 1 \mathrm{~K}$ & 9.4045 & 6.8931 & $0.2995(215)$ & $0.2049(101)$ & 14.94 & 114.30 & 31.529 \\
\hline $\mathrm{F} 2 \mathrm{~K}$ & 9.4017 & 6.8939 & $0.3320(222)$ & $0.2519(103)$ & 14.33 & 113.80 & 48.542 \\
\hline F5K & 9.3977 & 6.8913 & $0.3156(221)$ & $0.2379(102)$ & 14.11 & 114.06 & 43.887 \\
\hline $\mathrm{F} 10 \mathrm{~K}$ & 9.3934 & 6.8929 & $0.2953(223)$ & $0.2261(103)$ & 14.68 & 114.38 & 41.711 \\
\hline F20K & 9.3828 & 6.8927 & $0.2686(202)$ & $0.1846(95)$ & 14.30 & 115.27 & 29.309 \\
\hline
\end{tabular}

${ }^{a}$ Values in parentheses are the standard deviation $\times 10,000$.

Determination of the MES of the F-CAPs

The MES distributions of the two F-CAP series of 14 samples are presented in figure 4 . For all samples, the MES distributions at $0.2 \mathrm{mg} / \mathrm{l}$ solution fluoride and those at $2.0 \mathrm{mg} / \mathrm{l}$ solution fluoride in $\mathrm{pH} 5.7$ buffer are superposed. In addition, for the $4 \mathrm{~F}$-CAPs in the $3 \%$ series for which experiments were conducted in $\mathrm{pH} 5.0$ buffer at the two fluoride concentrations, the MES distributions are also superposed with each other (fig. $4 \mathrm{a}$, $c, e, g)$. 


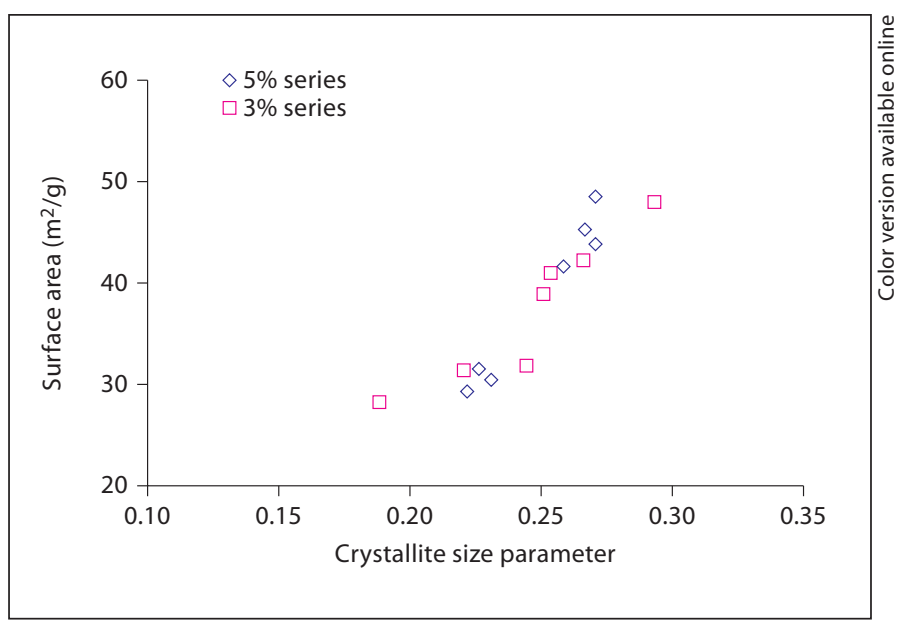

Fig. 3. Relationship between the crystallite size parameter and the specific surface area.

The solubilities of all of the F-CAPs, indicated by the mean $\mathrm{pI}_{\mathrm{FAP}}$ values, are listed in table 2 . The relationship between the mean $\mathrm{pI}_{\mathrm{FAP}}$ values of the F-CAPs and their microstrain parameters is presented in figure 5 . In addition, the mean $\mathrm{pI}_{\mathrm{FAP}}$ values and the microstrain parameters for some CAPs with no lattice incorporated fluoride, obtained from a previous study [Zhuang et al., 2001], are also plotted here. A linear regression line of the data points from the previous CAP study is also shown in figure 5. The data points for all the $14 \mathrm{~F}$-CAPs fall in line with the previous CAP data.

\section{Discussion}

In figure $2 \mathrm{a}$, we note that the crystallite unit cell aaxis value of the F-CAPs decreases as the fluoride substitution extent increases. The contraction in the a-axis indicates that the fluoride was incorporated into the mineral crystal lattice and was not just adsorbed to the surface. This result is in good agreement with the observations on F-CAPs of Okazaki et al. [1982] and the observations on fluoride-incorporated hydroxyl apatites of Moreno et al. [1977]. In addition, the differences in a-axis values between the two F-CAP series of different carbonate content are consistent with the observations of LeGeros [1991] on the carbonate content effect on the aaxis value. The unit cell c-axis values show little change with the addition of fluoride into the lattice within a series (table 2), but a comparison of the c-axis values between the two series of F-CAPs shows some differences, mainly in terms of the contribution of the different carbonate contents of the samples. This is also consistent with the observations of LeGeros [1991].

In one of our previous reports, we discussed in detail that the microstrain parameter is a better indicator of CAP crystallinity than the full width at half maximum (FWHM) of some reflection peaks of the X-ray diffraction profile, because both the imperfection of the crystallite (microstrain) and the crystallite size may contribute to peak broadening, and that the Rietveld refinement method may allow separation of the two contributions [Baig et al., 1999b]. In this study, we observed that fluoride incorporation into the CAP mineral lattice increases the mineral crystallinity, especially for high fluoride substitution extents as demonstrated in figure $2 \mathrm{~b}$. However, for low fluoride contents (from 0 to $2,000 \mu \mathrm{g} / \mathrm{g}$ ), there is a complicated relationship between the microstrain parameter and the extent of fluoride substitution. For the F-CAPs of high carbonate content (5\% series), the microstrain parameter first decreases and then increases; this might possibly be due to small variations of the carbonate content for this series which first decreases and then increases. For the 3\% series F-CAPs with a lower carbonate content, the microstrain parameter is relatively insensitive to the fluoride substitution extent over a wide range. Featherstone et al. [1983] also observed that when CAP contained $100 \mu \mathrm{g} / \mathrm{g}$ fluoride, there was no significant change of the FWHM of the 211 X-ray diffraction peak at $3 \%$ carbonate, but there was a significant narrowing of the peak at $6 \%$ carbonate. In addition, Okazaki et al. [1982] also observed that at high fluoride contents, the FWHM values for both the 002 peak and the 300 peak were smaller and there were fluctuations for the FWHM at low fluoride contents. Our observations are consistent with these previously reported results, but employing the microstrain parameter instead of the FWHM may allow for determining a more precise relationship between mineral crystallinity and the fluoride substitution extent. As can be seen in figure $2 \mathrm{~b}$, fluoride incorporation into the crystallite lattice only contributed modest changes to the apatite crystallinity as reflected by the microstrain parameter values.

Fig. 4. MES distributions of two series of F-CAPs. a 3\%-F0. b 3\%F300. c $3 \%-\mathrm{F} 1 \mathrm{~K}$. d $3 \%-\mathrm{F} 2 \mathrm{~K}$. e $3 \%-\mathrm{F} 5 \mathrm{~K}$. f $3 \%-\mathrm{F} 10 \mathrm{~K}$. g $3 \%-\mathrm{F} 20 \mathrm{~K}$. h 5\%-F0. i 5\%-F300. j 5\%-F1K. k 5\%-F2K. I 5\%-F5K. m 5\%-F10K. n $5 \%-F 20 \mathrm{~K}$. Solution conditions: $\diamond=\mathrm{pH} 5.7$ and $0.2 \mathrm{mg} / \mathrm{l} \mathrm{F}$; $\square=$ pH 5.7 and $2.0 \mathrm{mg} / \mathrm{l} \mathrm{F}$; $\triangle$ pH 5.0 and $0.2 \mathrm{mg} / \mathrm{l} \mathrm{F}$; $\bigcirc=\mathrm{pH} 5.0$ and $2.0 \mathrm{mg} / \mathrm{l} \mathrm{F}$. 


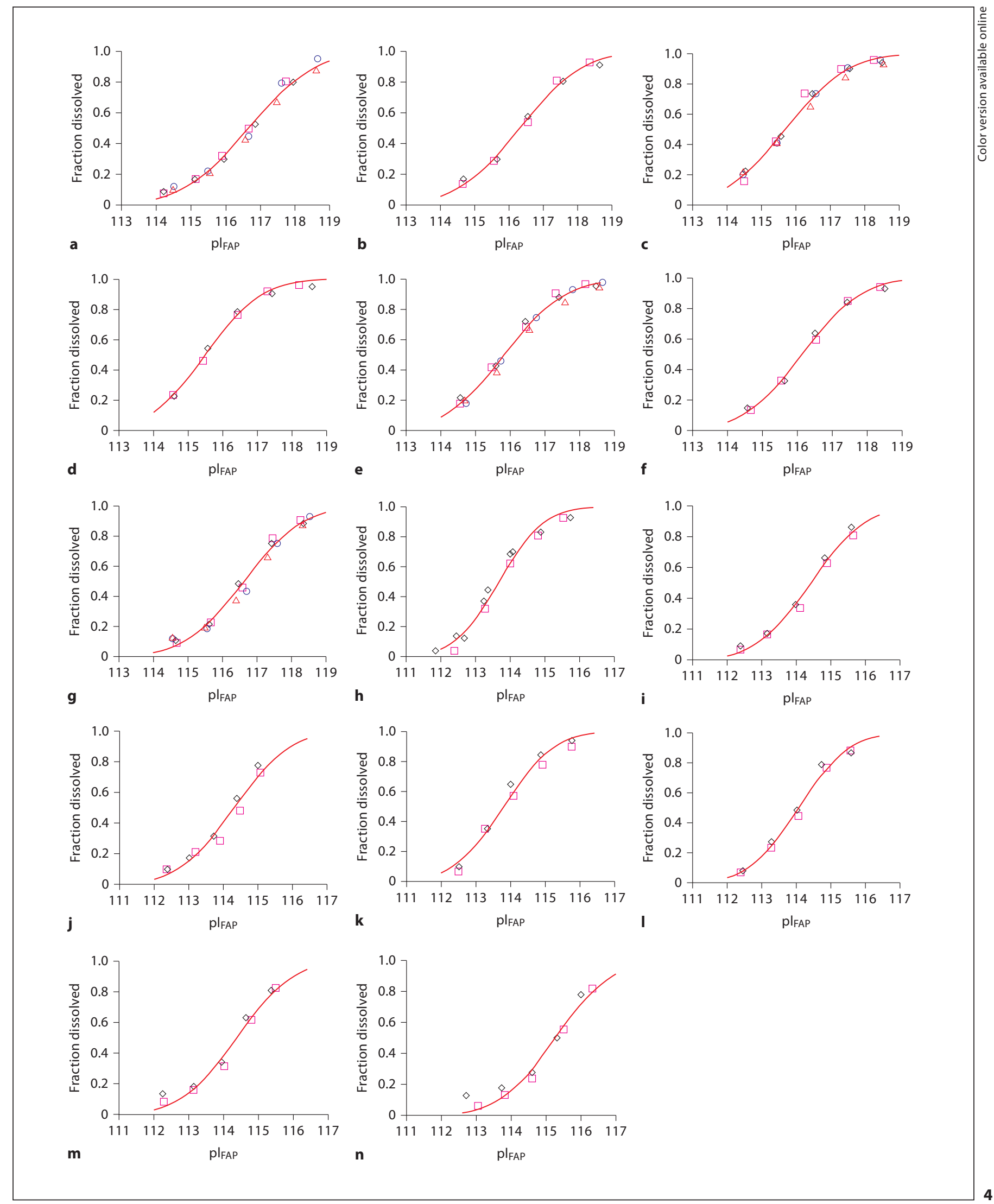




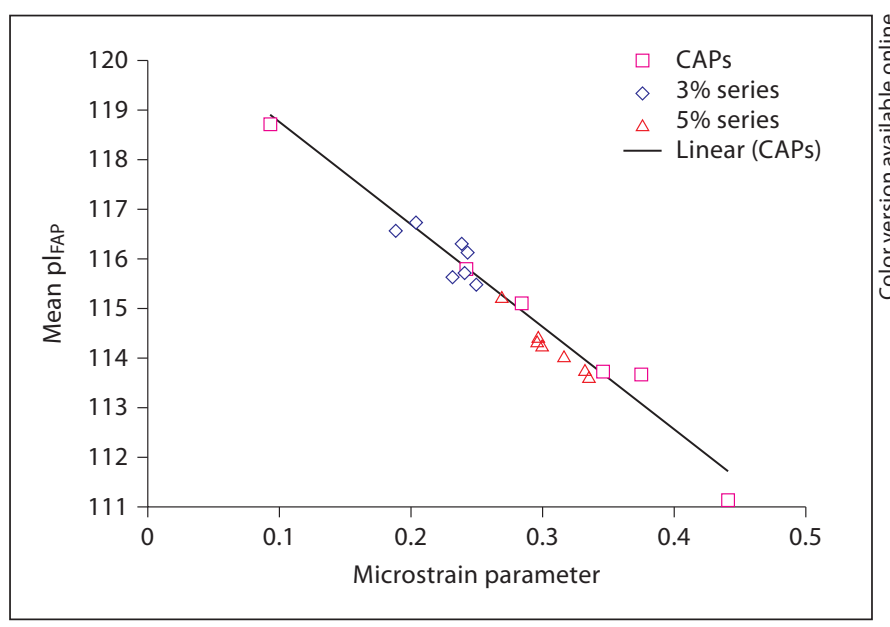

Fig. 5. Relationship between the microstrain parameter of the apatite and its corresponding mean $\mathrm{pI}_{\mathrm{FAP}}$ determined from MES experiments. Previous CAP results are from Zhuang et al. [2001]. The solid line is the linear regression of the CAP results with a linear regression equation of $y=-20.675 x+120.84$ and $R^{2}=$ 0.9766 .

This modest change in apatite crystallinity by fluoride incorporation corresponds very well to the modest shifts of the F-CAP MES distribution curves in fluoride-containing acetate buffers (table 2). The most dramatic shift in the MES distribution curve is exhibited with the 5\%F20K sample, which has a high carbonate content and a fluoride substitution extent of about 0.5 . Compared to the mean $\mathrm{pI}_{\mathrm{FAP}}$ of $5 \%$-F0, which is the sample with the same high carbonate content but zero fluoride substitution, the mean $\mathrm{pI}_{\mathrm{FAP}}$ of the $5 \%$-F20K sample shifts $1.6 \mathrm{pI}_{\mathrm{FAP}}$ units to the right, or in the less soluble direction. In other words, the $5 \%$-F20k sample is $1.6 \mathrm{pI}_{\mathrm{FAP}}$ units less soluble than the 5\%-F0 sample (or the fluoride incorporation reduces its solubility by $1.6 \mathrm{pI}_{\mathrm{FAP}}$ units). However, for the F-CAPs with the lower carbonate content, the shift of the mean $\mathrm{pI}_{\mathrm{FAP}}$ (the mean $\mathrm{pI}_{\mathrm{FAP}}$ difference between $3 \%-\mathrm{F} 0$ and $3 \%-\mathrm{F} 20 \mathrm{~K}$ ) is insignificant, which indicates that the fluoride incorporation should have little impact on the 3\% series solubilities. Featherstone et al. [1983] also observed that fluoride incorporation could significantly change the dissolution rate of a CAP of high carbonate content $(6 \%)$ even with only $100 \mu \mathrm{g} / \mathrm{g}$ fluoride content, while showing no significant change for a CAP possessing a lower carbonate level (3\%).

Okazaki et al. [1982] attempted to study the fluoride lattice effect on the apatite crystallinity, solubility, and dissolution rate but could not successfully establish a relationship between the apatite crystallinity and the solu- bility, possibly because the authors assumed that the solubility was controlled by the bulk solid composition of the apatite and did not consider the possibility of the apatite dissolution behavior being governed by a surface complex with a composition different from that of the bulk solid. In addition, the fluoride released into the solution during the solid dissolution could also affect the apatite solubility. In the present study, all of the solubility experiments were conducted in solutions with either 0.2 or $2 \mathrm{mg} / \mathrm{l}$ fluoride present before the experiment, and the solution fluoride concentration during the experiment changed by less than $10 \%$. Therefore, the fluoride released from apatite during dissolution would not affect its solubility determination under our experimental conditions. Additionally, the MES distributions of all of the F-CAPs were found to be clearly consistent with the FAP surface complex governing the solubility behavior in the acetate buffer solutions with fluoride present. Also, a linear correlation could be successfully established between the MES and the crystallinity no matter how much fluoride was incorporated into the F-CAPs (fig. 5). These results once again suggest that the microstrain parameter is a good indicator of the crystallinity of the F-CAPs, and the MES of the F-CAPs is a single-valued function of the microstrain parameter.

The MES distribution approach has provided a means to quantitatively evaluate the lattice fluoride effect and also to directly compare the relative importance of the solution fluoride effect and the lattice fluoride effect. As mentioned above, the most significant lattice fluoride effect in the present study is the case of the $1.6 \mathrm{pI}_{\mathrm{FAP}}$ unit shift for the 5\%-F20K sample compared to the 5\%-F0 sample, with about $50 \%$ fluoride substitution for hydrox$\mathrm{yl}$ ion in the apatite. It has also been found previously that CAP samples exhibit the MES distribution phenomenon in acetate buffers without fluoride present and in this case the MES distributions are governed by an HAP surface complex [Chhettry et al., 1999]. For this situation we may use the mean $\mathrm{pI}_{\mathrm{HAP}}$ (the solution IAP value based on the HAP stoichiometry $\left[-\log \left(\mathrm{a}_{\mathrm{Ca}}{ }^{10} \mathrm{a}_{\mathrm{PO}_{4}}{ }^{6} \mathrm{a}_{\mathrm{OH}}{ }^{2}\right)\right]$ at which $50 \%$ of the apatite was dissolved) to denote its solubility in acetate buffer without fluoride present. For a particular CAP preparation (with relatively high crystallinity) without fluoride incorporation, its mean $\mathrm{pI}_{\mathrm{FAP}}$ value (the IAP value based on the FAP stoichiometry of an MES solution with fluoride present in which $50 \%$ of the CAP would dissolve) is close to its mean $\mathrm{pI}_{\mathrm{HAP}}$ value (the IAP value based on HAP stoichiometry of an MES solution with no fluoride present in which $50 \%$ of the CAP would dissolve). We demonstrated this relationship in a previ- 
ous study [Papangkorn et al., 2008]. As a specific example, the CAP sample 3\%-F0 shows solubility with a mean $\mathrm{pI}_{\mathrm{FAP}}$ value of 116.7 in the MES dissolution media with fluoride present, and we would expect this CAP sample to show solubility with a mean $\mathrm{pI}_{\mathrm{HAP}}$ value very close to 116.7 in MES dissolution media with no fluoride present. In other words, we would expect $50 \%$ of the $3 \%$-F0 sample to be dissolved in an acetate buffer MES dissolution medium with no fluoride present and with a $\mathrm{pI}_{\mathrm{HAP}}$ value of 116.7. However, if $0.2 \mathrm{mg} / \mathrm{l}$ fluoride is added into this MES dissolution media (which has a $\mathrm{pI}_{\mathrm{HAP}}$ value of 116.7 at $\mathrm{pH} 5.0$ or $\mathrm{pH}$ 5.7), its $\mathrm{pI}_{\mathrm{FAP}}$ value will be 110.7 at $\mathrm{pH} 5.7$ and 109.2 at $\mathrm{pH}$ 5.0. Based on figure 4a, it is obvious that none of the 3\%-F0 would dissolve in the MES solution with a $\mathrm{pI}_{\mathrm{FAP}}$ of 110.7 or 109.2. In order to achieve the same solubility as before adding the $0.2 \mathrm{mg} / \mathrm{l}$ fluoride into the solution, which is to dissolve $50 \%$ of the $3 \%-\mathrm{F} 0$ in the MES solution containing $0.2 \mathrm{mg} / \mathrm{l}$ fluoride, the solution $\mathrm{pI}_{\mathrm{FAP}}$ needs to be 116.7. This corresponds to 6.0 units of $\mathrm{pI}_{\mathrm{FAP}}$ difference for the $\mathrm{pH} 5.7$ solution and 7.5 units of $\mathrm{pI}_{\mathrm{FAP}}$ difference for the $\mathrm{pH} 5.0$ solution, which we assumed as the solution fluoride effect for the $0.2 \mathrm{mg} / \mathrm{l}$ concentration. This solution fluoride effect at $0.2 \mathrm{mg} / \mathrm{l}(6.0$ units to 7.5 units shift depending upon the solution $\mathrm{pH}$ ) is obviously much greater than the maximum $1.6 \mathrm{pI}_{\mathrm{FAP}}$ units resulting from $50 \%$ fluoride lattice incorporation found in the present study. This finding supports the current view that the lattice fluoride effect is a minor effect compared to the solution fluoride effect [Thylstrup, 1990; Featherstone, 2000].

We used a relatively high solution-to-solid ratio for the MES experiments with or without the fluoride present for the purpose of maintaining a relatively unchanged pI value even after the solid dissolved into the MES solution. The in vivo situation would almost certainly be more complex. In a developing caries lesion, a much lower solution-to-solid ratio would be expected. It would also be possible that the fluoride in saliva could either adsorb on the tooth surface or precipitate out as a solid phase on the tooth. On the other hand, the adsorbed fluoride or precipitated fluoride solid phase could still act as a fluoride reservoir for supplying fluoride to the microenvironment [Chow, 1990]. In any case, the fluoride concentration in the saliva could be significantly lower than the $0.2 \mathrm{mg} / \mathrm{l}$ we used in the MES study, and thus possibly this may correspond to a smaller solution fluoride effect.

In summary, this investigation has demonstrated that the two series of F-CAPs show the MES distribution behavior in weak acid buffers with solution fluoride present, and this MES distribution is governed by a surface complex with the stoichiometry of FAP. The microstrain parameter can be used to quantitatively describe the crystallinity of the F-CAPs. The lattice fluoride shows a modest effect on mineral crystallinity, and this modest crystallinity increase has been observed only in the F-CAPs at the highest fluoride substitution extent (50\%) with a high carbonate content. A linear correlation between the microstrain parameter of the F-CAPs and the corresponding MES (mean $\mathrm{pI}_{\mathrm{FAP}}$ ) of the F-CAPs has been found. This correlation line falls on the same line as previous results obtained with CAPs with no lattice incorporated fluoride. All of the present results indicate that lattice incorporated fluoride would have only a minor effect on the solubility and the crystallinity of F-CAPs, while solution fluoride would show significant effects on reducing apatite solubility.

\section{Acknowledgments}

This study was supported by NIDCR grant DE 06569 .

\section{Disclosure Statement}

The authors declare no conflicts of interest.

\section{References}

-Baig AA, Fox JL, Hsu J, Wang Z, Otsuka M, Higuchi WI, Legeros RZ: Effect of carbonate content and crystallinity on the metastable equilibrium solubility behavior of carbonated apatites. J Colloid Interface Sci 1996; 179:608-617.

Baig AA, Fox JL, Wang Z, Higuchi WI, Miller SC, Barry AM, Otsuka M: Metastable equilibrium solubility behavior of bone mineral. Calcif Tissue Int 1999a;64:329-339.
Baig AA, Fox JL, Young RA, Wang Z, Hsu J, Higuchi WI, Chhettry A, Zhuang H, Otsuka M: Relationships among carbonated apatite solubility, crystallite size, and microstrain parameters. Calcif Tissue Int 1999b;64:437449 .

Barry AB, Zhuang H, Baig AA, Higuchi WI: Effect of fluoride pretreatment on the solubility of synthetic carbonated apatite. Calcif Tissue Int 2003;72:236-242. 
Brown WE, Gregory TM, Chow LC: Effects of fluoride on enamel solubility and cariostasis. Caries Res 1977;11(suppl 1):118-141.

-Chhettry A, Wang Z, Hsu J, Fox JL, Baig AA, Barry AM, Zhuang H, Otsuka M, Higuchi WI: Metastable equilibrium solubility distribution of carbonated apatite as a function of solution composition. J Colloid Interface Sci 1999;218:57-67.

Chow LC: Tooth-bound fluoride and dental caries. J Dent Res 1990;69:595-600, discussion 634-636.

Conway E: Microdiffusion Analysis and Volumetric Error. London, Crosby Lockwood, 1962.

Dean H, Arnold F, Elvove E: Domestic water and dental caries. Public Health Rep 1942;57: 1155-1179.

DePaola PF: Reaction paper: the use of topical and systemic fluorides in the present era. J Public Health Dent 1991;51:48-52.

Driessens F: Thermodynamics of the solubility behavior of fluorohydroxyapatite solid solution. Ber Bunsenges Phys Chem 1979;83: 583-586.

Driessens FC: Fluoride incorporation and apatite solubility. Caries Res 1973;7:297-314.

Featherstone JD: The science and practice of caries prevention. J Am Dent Assoc 2000;131: 887-899.

Featherstone JD, Shields CP, Khademazad B, Oldershaw MD: Acid reactivity of carbonated apatites with strontium and fluoride substitutions. J Dent Res 1983;62:1049-1053.

-Gee A, Domingues L, Dietz V: Constituents in sugar. Anal Chem 1954;26:1487-1492.

Glenn FB: Preeruptive effect of fluoride. J Am Dent Assoc 2000;131:1674, 1676, 1678.

-Glenn FB, Glenn WD 3rd, Duncan RC: Fluoride tablet supplementation during pregnancy for caries immunity: a study of the offspring produced. Am J Obstet Gynecol 1982;143: 560-564.

Hsu J: Dissolution Mechanism of Carbonate Containing Apatite; PhD thesis, University of Utah, Salt Lake City, 1993.

-Hsu J, Fox JL, Higuchi W, Powell G, Otsuka M, Baig A, LeGeros R: Metastable equilibrium solubility behavior of carbonated apatites. J Colloid Interface Sci 1994;167:414-423.
LaMer VK: The solubility behavior of hydroxyapatite. J Phys Chem 1962;66:973-978.

-Larsen MJ, Jensen SJ: The hydroxyapatite solubility product of human dental enamel as a function of $\mathrm{pH}$ in the range 4.6-7.6 at $20 \mathrm{de}$ grees C. Arch Oral Biol 1989;34:957-961.

LeGeros RZ: Calcium Phosphates in Oral Biology and Medicine. Basel, Karger, 1991, vol 15.

LeGeros RZ, Glenn FB, Lee DD, Glenn WD Some physico-chemical properties of deciduous enamel of children with and without pre-natal fluoride supplementation (PNF). J Dent Res 1985;64:465-469.

Levinskas G, Neuman W: The solubility of bone mineral. 1. solubility studies of synthetic hydroxyapatite. J Phys Chem 1955;59:164-168.

MacGregor J, Nordin B: Equilibration studies with human bone powder. J Biol Chem 1960; 235:1215-1218.

Margolis HC, Moreno EC, Murphy BJ: Effect of low levels of fluoride in solution on enamel demineralization in vitro. J Dent Res 1986; 65:23-29.

McKay F: The study of mottled enamel (dental fluorosis). J Am Dent Assoc 1952;44:133137.

Mir NA, Higuchi WI, Hefferren JJ: The mechanism of action of solution fluoride upon the demineralization rate of human enamel. Arch Oral Biol 1969;14:901-920.

Moreno EC, Kresak M, Zahradnik RT: Fluoridated hydroxyapatite solubility and caries formation. Nature 1974;247:64-65.

Moreno EC, Kresak M, Zahradnik RT: Physicochemical aspects of fluoride-apatite systems relevant to the study of dental caries. Caries Res 1977;11(suppl 1):142-171.

Okazaki M, Aoba T, Doi Y, Takahashi J, Moriwaki Y: Solubility and crystallinity in relation to fluoride content of fluoridated hydroxyapatites. J Dent Res 1981;60:845-849.

-Okazaki M, Takahashi J, Kimura H, Aoba T: Crystallinity, solubility, and dissolution rate behavior of fluoridated $\mathrm{CO}_{3}$ apatites. J Biomed Mater Res 1982;16:851-860.

Papangkorn K, Yan G, Heslop DD, Moribe K, Baig AA, Otsuka M, Higuchi WI: Influence of crystallite microstrain on surface complexes governing the metastable equilibrium solubility behavior of carbonated apatites. J Colloid Interface Sci 2008;320:96-109.
Patel PR, Brown WE: Thermodynamic solubility product of human tooth enamel: powdered sample. J Dent Res 1975;54:728-736.

Rootare HM, Deitz VR: Solubility product phenomena in hydroxyapatite water system. J Colloid Sci 1962;17:179-206.

Rosin-Grget K, Lincir I: Current concept on the anticaries fluoride mechanism of the action. Coll Antropol 2001;25:703-712.

Sarkar BC, Chauhan UP: A new method for determining micro quantities of calcium in biological materials. Anal Biochem 1967;20: 155-166.

Takagi S, Liao H, Chow LC: Effect of toothbound fluoride on enamel demineralization/ remineralization in vitro. Caries Res 2000; 34:281-288.

Thylstrup A: Clinical evidence of the role of preeruptive fluoride in caries prevention. J Dent Res 1990;69:742-750, discussion 820-823.

Varughese K, Moreno EC: Crystal growth of calcium apatites in dilute solutions containing fluoride. Calcif Tissue Int 1981;33:431-439.

$\checkmark$ Widenheim J, Birkhed D, Granath L, Lindgren G: Preeruptive effect of $\mathrm{NaF}$ tablets on caries in children from 12 to 17 years of age. Community Dent Oral Epidemiol 1986;14:1-4.

-Wong L, Cutress TW, Duncan JF: The influence of incorporated and adsorbed fluoride on the dissolution of powdered and pelletized hydroxyapatite in fluoridated and non-fluoridated acid buffers. J Dent Res 1987;66:17351741.

>Young R, Sakthivel A, Moss T, Paiva-Santos C: DBWS-9411 - an upgrade of the DBWS** programs for Rietveld refinement with PC and mainframe computers. J Appl Crystallogr 1995;28:366-367.

-Zhuang H, Baig AA, Fox JL, Wang Z, Colby SJ, Chhettry A, Higuchi WI: Metastable equilibrium solubility behavior of carbonated apatites in the presence of solution fluoride. J Colloid Interface Sci 2000;222:90-96.

Zhuang H, Baig AA, Zhang N, Chhettry A, Higuchi WI: Relationships involving metastable equilibrium solubility, surface complexes, and crystallite disorder with carbonated apatites. Calcif Tissue Int 2001;69:343-349. 